\title{
Effect of glazing configuration as an energy-saving strategy in naturally ventilated greenhouses for strawberry (Seolhyang sp.) cultivation
}

\author{
Timothy Denen Akpenpuun, ${ }^{1,2}$ Wook Ho Na, ${ }^{2}$ Qazeem Opeyemi Ogunlowo, ${ }^{3,4}$ Anis Rabiu, ${ }^{3}$ \\ Misbaudeen Aderemi Adesanya, ${ }^{3}$ Kwame Sasu Addae, ${ }^{5}$ Hyeon Tae Kim, ${ }^{6}$ Hyun-Woo Lee ${ }^{2,3}$ \\ ${ }^{1}$ Department of Agricultural and Biosystems Engineering, University of Ilorin, Ilorin, Nigeria; ${ }^{2}$ Smart Agriculture \\ Innovation Centre, Kyungpook National University, Daegu, Korea; ${ }^{3}$ Department of Agricultural Civil Engineering, \\ College of Agricultural and Life Sciences, Kyungpook National University, Daegu, Korea; ${ }^{4}$ Federal College of \\ Agriculture, Moor Plantation, Ibadan, Nigeria; ${ }^{5}$ Department of Agriculture, Kwahu South Municipal, Kwahu, \\ Mpraeso, Ghana; ${ }^{6}$ Department of Bio-Industrial Machinery Engineering, Gyeongsang National University (Institute of \\ Agricultural and Life Sciences), Jinju, Korea
}

\begin{abstract}
Strawberry cultivation is highly dependent on environmental parameters and energy in winter. Two gothic greenhouses with different glazing material combinations, i.e. polyolefin-thermal screen (PoTS) and polyolefin-thermal screen-polyethylene (PoTSPe), were used for strawberry cultivation. The energy-saving capabilities of the two configurations and their impact on the microclimates of the greenhouses were investigated. Temperature, relative humidity, vapor pressure deficit, leaf temperature, and solar radiation over the experimental period in the PoTS greenhouse were $13.0 \pm 2.3^{\circ} \mathrm{C}, 75.8 \pm 6.5 \%, 0.4 \pm 0.1 \mathrm{kPa}, 13.6 \pm 1.7^{\circ} \mathrm{C}$, and $168.8 \pm 82.3 \mathrm{~W} / \mathrm{m}^{2}$, respectively, whereas in the PoTSPe setup they were $13.1 \pm 2.3^{\circ} \mathrm{C}, 80.0 \pm 5.7 \%, 0.3 \pm 0.1 \mathrm{kPa}, 13.5 \pm 1.6^{\circ} \mathrm{C}$, and
\end{abstract}

Correspondence: Hyun-Woo Lee, Smart Agriculture Innovation Centre; and Department of Agricultural Civil Engineering, College of Agricultural and Life Sciences, Kyungpook National University, Daegu 702-701, Korea. Tel.: +82.53.850.5736. E-mail: whlee@knu.ac.kr

Key words: Fuel consumption; humidity; microclimate; temperature; winter.

Acknowledgements: this work was supported by the Korea Institute of Planning and Evaluation for Technology in Food, Agriculture, Forestry and Fisheries (IPET) through the Agriculture, Food and Rural Affairs Convergence Technologies Program for Educating Creative Global Leader, funded by the Ministry of Agriculture, Food and Rural Affairs (MAFRA) (717001-7). This research was supported by the Basic Science Research Program through the National Research Foundation of Korea (NRF) funded by the Ministry of Education (NRF2019R1I1A3A01051739).

Received for publication: 30 March 2021.

Accepted for publication: 24 April 2021.

CC Copyright: the Author(s), 2021

Licensee PAGEPress, Italy

Journal of Agricultural Engineering 2021; LII:1177

doi:10.4081/jae.2021.1177

This article is distributed under the terms of the Creative Commons Attribution Noncommercial License (by-nc 4.0) which permits any noncommercial use, distribution, and reproduction in any medium, provided the original author(s) and source are credited.
$183.1 \pm 90.5 \mathrm{~W} / \mathrm{m}^{2}$. The mean fuel consumption by the PoTS and PoTSPe greenhouses were 5.5 and $3.5 \mathrm{~L}$, respectively. The performance analysis shows that both greenhouses were able to maintain the environmental parameters and leaf temperature within the recommended ranges, although more energy was consumed with PoTS. A higher yield was obtained in the PoTS greenhouse, which, however, was not significantly different from the PoTSPe yield.

\section{Introduction}

In winter, especially at night, vapor often condenses and accumulates on the inner surface of glazing materials or thermal screens, and drops due to the temperature gradient between the greenhouse microclimate and the ambient environment. The fall of condensate and rainwater onto crops creates more favourable conditions for the growth and multiplication of disease-causing fungi (Mijinyawa, 2011; Hernández et al., 2017), which consequently lead to poor yield in terms of both quantity and quality. However, conventional thermal screens are rarely used in greenhouses in temperate regions, since they require a significant investment (Hernández et al., 2017).

Fixed impermeable thermal screens affect greenhouse air temperature, humidity, and water condensation by reducing heat loss, natural ventilation and leakage rates, air volume around the crop, transmission of short-wave radiation, and depletion of daytime $\mathrm{CO}_{2}$ as the greenhouse air volume directly in contact with crops is reduced (Jayasekara et al., 2018; Omobowale, 2019). Hernández et al. (2017) reported that the greatest heat loss reduction in unheated greenhouses was achieved when a permeable material, aluminized on one side, was installed with the aluminized side facing directly upwards. However, they concluded that this is not applicable to impermeable fixed screens. Energy-saving technologies are increasingly used in the greenhouse industry to reduce fossil fuel consumption, which will invariably reduce the cost of greenhouse production. Most heated greenhouses in temperate regions have very low leakage ventilation rates, therefore thermal screens are installed to conserve energy (Hernández et al., 2017). These modifications, however, increasingly make humidity control around the crop canopy difficult, as humidity is extremely high during the heating period and requires dehumidification with cold outside air, thus increasing the heat energy consumption (Hernández et al., 2017). Thermal screens in such greenhouses are usually unfolded over the crop at sunset and folded at sunrise, although the optimal opening strategy depends on external weath- 
er conditions. Thermal screens save energy, yet they influence the greenhouse microclimate and can therefore affect crop behaviour (Katsoulas and Kittas, 2008; Hernández et al., 2017).

Overall, little is reported in the literature on the effects of using multiple layers of polyolefin or polyethylene in combination with a thermal screen on the greenhouse microclimate for low-cost greenhouses in the winter (Bonachela et al., 2012; Piscia et al., 2013), and even less information is available about the effect of these glazing materials on crop response. Therefore, the main objective of the present study was to quantify the effect of a single layer of polyolefin (single-layer), and single polyolefin and polyethylene layers (double-layer) in combination with a permeable thermal screen on the greenhouse microclimate and crop response in naturally ventilated greenhouses in a winter climate.

\section{Materials and methods}

\section{Study area}

The experiment was carried out in winter (October 3 to December 30, 2020) at the Smart Agriculture Innovation Centre, Kyungpook National University, Buk-gu, Daegu, South Korea. Daegu Metropolitan City is located between $35.60^{\circ}$ and $36.02^{\circ}$ north latitude and $128.35^{\circ}$ and $128.77^{\circ}$ east longitude, and is about $48 \mathrm{~m}$ AMSL. The climate is humid subtropical with an annual average relative humidity $(\mathrm{RH})$, rainfall, daily photoperiod, minimum temperature, and maximum temperature of $61.6 \%, 1131.5$ $\mathrm{mm}, 6.2$ hours, $-10.1^{\circ} \mathrm{C}$, and $14.6^{\circ} \mathrm{C}$, respectively (Jayasekara et al., 2018; Rasheed et al., 2019). There are four seasons in Daegu: spring (March-May), summer (June-August), fall (SeptemberNovember), and winter (December-February). Food crops cultivated in Daegu include rice, cabbage, strawberries, and cherries in spring; as well as apricots, potatoes, tomatoes, apples, chestnuts, persimmon, and sweet potatoes (Choi et al., 2019).

\section{Experimental procedure}

The two gothic greenhouses used in this experiment were located at the Smart Agriculture Innovation Centre, Kyungpook National University, Daegu (latitude: $35.87^{\circ} \mathrm{N}$, longitude: $128.60^{\circ}$ $\mathrm{W}$, altitude: $1100 \mathrm{~m}$ ) in the east-west orientation for optimum solar radiation reception, in the study area in winter. The greenhouses had the same structural configurations (gothic roofed), but one greenhouse was glazed with polyolefin, thermal screen, and polyethylene (PoTSPe) and equipped with a side vent and double ridge vents (one facing north and the other south) (Figure 1), whereas the second greenhouse was glazed with polyolefin and thermal screen (PoTS) and was equipped with a side vent and single roof vent (facing south) (Figure 2). The choice of polyethylene as the inner layer (second layer) in the PoTSPe greenhouse was due to economic reason, as polyolefin is much more expensive than polyethylene. Also, polyethylene was chosen over polyolefin, because the polyethylene layer will not be exposed to direct solar radiation, but was solely intended to serve as an insulator on the thermal screen inner surface. The thickness and solar radiation transmittance of the polyolefin and polyethylene films were $150 \mu \mathrm{m}$ and $91 \%$ for all solar radiation wavelengths, and $50 \mu \mathrm{m}$ and $88 \%$ for all solar radiation wavelengths, respectively, and the thermal screen properties were thickness $(3.5 \mathrm{~mm})$, thermal conductivity $\left(0.037 \mathrm{Wm}^{-1} \mathrm{~K}^{-1}\right)$, thermal radiation transmittance $(<0.001 \%)$, reflectance $(0.10)$, and emittance $(0.90)$ for both greenhouses. The thermal screen in both greenhouses was retractable and the second polyolefin layer in the PoTSPe greenhouse also. The thermal screens open during the day (08:30 a.m.) and close at night (18:00 p.m.) making both green- houses behave as a single-layer polyolefin greenhouse during the day, but not at night. The roof and side vents automatically opened when the greenhouses air temperature exceeded $21\left(21.5^{\circ} \mathrm{C}\right)$ and $23^{\circ} \mathrm{C}\left(23.5^{\circ} \mathrm{C}\right)$, respectively, whereas the heating system (boiler) set temperature range was $7.5-8.5^{\circ} \mathrm{C}$ for the activation and deactivation of the boiler, as $8^{\circ} \mathrm{C}$ is the lowest temperature recommended for strawberry growth and development (Bradford et al., 2010). The optimum air temperature range in the literature for optimum strawberry growth and development is between 18 and $24^{\circ} \mathrm{C}$. A spiral heat dissipating pipe, placed under the greenhouse beds, was connected to the boiler tanker to circulate hot water all along the pipe in order to raise the rootzone and greenhouse air space temperature. Diesel was used to run the boiler and consumption was recorded using a digital flow meter. The dimensions of both greenhouses were $24 \times 7 \times 4 \mathrm{~m}^{3}$ with a planting area of $18 \times 4.5 \mathrm{~m}\left(81 \mathrm{~m}^{2}\right)$. The total floor area of each greenhouse was $184.8 \mathrm{~m}^{2}$, and the area of the side and ridge vents were $30 \%$ of the greenhouse floor area. In order to aid air circulation and ensure uniform environmental conditions within the greenhouses, four $0.5-\mathrm{hp}$ and $25 \mathrm{~cm}$ window-sized aircirculating fans were installed at the height of $1.9 \mathrm{~m}$ from the greenhouse floor in the east and west ends. Greenhouse air temperature, $\mathrm{RH}$, and SR were measured continuously. Three air temperature and RH sensors ( (accuracy: $\pm 0.25^{\circ} \mathrm{C}, \mathrm{HOBO}$ PRO v2 U23 Pro v2, ONSET, $3 \mathrm{~min}$ in air moving $1 \mathrm{~m} / \mathrm{s} ; 30 \mathrm{~s}$ in stirred water, USA) were installed per row (front, middle, and end) $1.54 \mathrm{~m}$ from the greenhouse floor. The solar radiation sensors (accuracy: $\pm 10 \mathrm{~W} / \mathrm{m}^{2}$; Response time: $<18$ s: Non-linearity: $<1 \%$, Spectral Range: 300 to $2800 \mathrm{~nm}$, Directional Error: $<20 \mathrm{~W} / \mathrm{m}^{2}$; Tilt Error: $<2 \%$; CMP3 Pyranometer, KIPP \& ZONEN, The Netherlands) was placed at the top of the plant canopy to measure SR from 7:00 to 19:00. The experiment began on 03/10/2020 and ended on 03/03/2021, five months after transplanting. Strawberries of the Seolhyang variety were used as the test crop and planted on elevated greenhouse beds

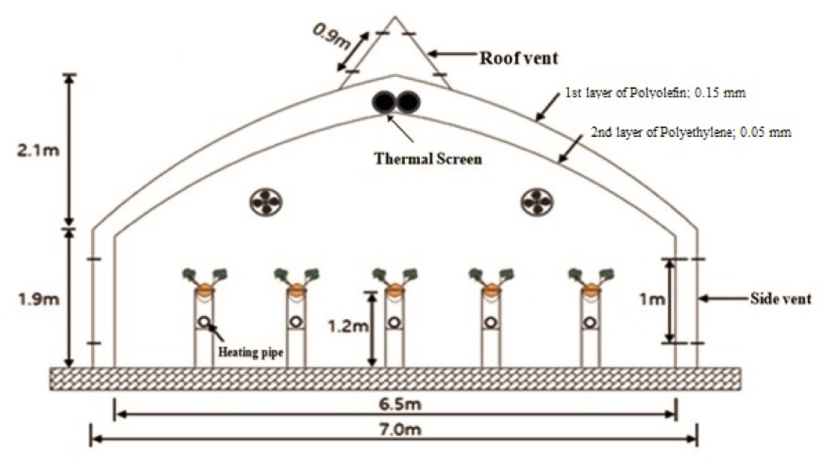

Figure 1. Polyolefin-thermal screen-polyethylene greenhouse.

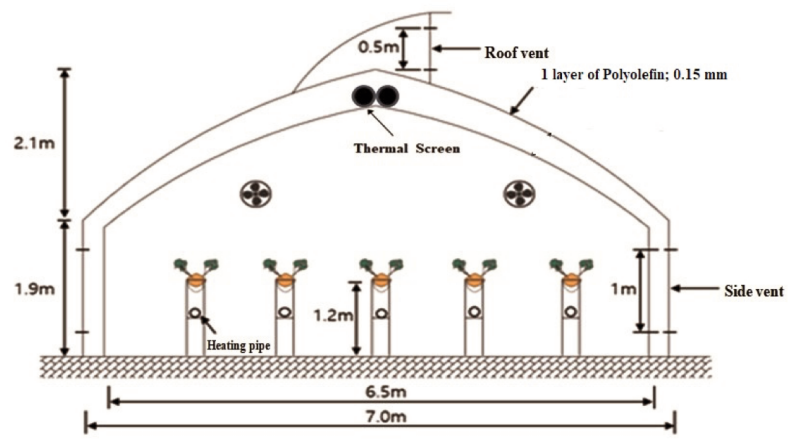

Figure 2. Polyolefin-thermal screen greenhouse. 
which were $76 \mathrm{~cm}$ wide and $1500 \mathrm{~cm}$ long. The crop and bed spacing were 25 and $60 \mathrm{~cm}$, respectively, with 132 plants per bed and a total plant population per greenhouse of 660 plants. The orientation of the beds was the same as that of the greenhouses. The irrigation and fertigation of the plants in both greenhouses was achieved with the same open-loop drip irrigation system. The irrigation and fertigation interval, duration, and number per day were $90 \mathrm{~min}, 3 \mathrm{~min}$, and 5 times, respectively, beginning at 08:30 am. The standard cultivating practices adopted by Fernandez et al., (2001) were followed, and bumblebees (Bombus terrestris L.) were introduced in both greenhouses for active pollination.

\section{Data recording and analysis}

The greenhouse air temperature, $\mathrm{RH}$ and solar radiation were measured continuously. The air temperature and RH sensors (accuracy: $\pm 0.25^{\circ} \mathrm{C}, \mathrm{HOBO}$ PRO v2 U23 Pro v2, ONSET, $3 \mathrm{~min}$ in air moving $1 \mathrm{~m} / \mathrm{s} ; 30 \mathrm{~s}$ in stirred water, USA) were installed in each row (front, middle and end of a row) at $1.54 \mathrm{~m}$ from the greenhouse floor. A leaf temperature sensor (accuracy: \pm 8 seconds per month in $0^{\circ}$ to $40^{\circ} \mathrm{C}$ and \pm 30 seconds per month in $-40^{\circ}$ to $60^{\circ} \mathrm{C}$, HOBO RX3000, ONSET, USA), and solar radiation sensors (accu- racy: $\pm 10 \mathrm{~W} / \mathrm{m}^{2}$; response time: $<18 \mathrm{~s}$ : non-linearity: $<1 \%$, spectral range: 300 to $2800 \mathrm{~nm}$, directional error: $<20 \mathrm{~W} / \mathrm{m}^{2}$; tilt error: $<2 \%$; CMP3 Pyranometer, KIPP \& ZONEN, The Netherlands) were placed in the plant canopy to measure the total solar radiation. Data were recorded at an interval of $10 \mathrm{~min}$. However, the vapor pressure deficit (VPD) was derived from the temperature and relative humidity data using Equations 1 and 2. The yield was measured in terms of weight of berry fruits per bed and greenhouse.

$$
P_{s}=610.78 \times \exp \left(\left(\frac{T}{T+238.3}\right) \times 17.27\right)
$$

$$
\text { Vapour pressure deficit, } \mathrm{kPa}=\frac{\left(1-\left(\frac{\mathrm{RH}}{100}\right)\right) \times \mathrm{P}_{\mathrm{s}}}{1000}
$$

where, $\mathrm{P}_{\mathrm{s}}, \mathrm{T}$ and $\mathrm{RH}$ are saturation vapor pressure $(\mathrm{Pa})$, greenhouse air temperature $\left({ }^{\circ} \mathrm{C}\right)$ and humidity $(\%)$.

The data collected was analysed using statistical tools, namely, analysis of variance (ANOVA) and descriptive statistics.

\begin{tabular}{|c|c|c|c|c|c|c|}
\hline Parameters & Temperature, ${ }^{\circ} \mathrm{C}$ & RH, $\%$ & VPD, kPa & $\mathrm{SR}, \mathrm{W} / \mathrm{m}^{2}$ & DWPT, ${ }^{\circ} \mathrm{C}$ & Fuel consumption, L \\
\hline Mean & 13.0 & 75.8 & 0.4 & 151.9 & 7.6 & 5.7 \\
\hline Variance & 5.1 & 41.9 & 0.0 & 10354.5 & 13.5 & 19.8 \\
\hline Standard deviation & 2.3 & 6.5 & 0.1 & 101.8 & 3.7 & 4.5 \\
\hline Minimum & 8.9 & 65.1 & 0.1 & 8.7 & -5.1 & 1.2 \\
\hline Maximum & 20.3 & 92.4 & 0.6 & 549.8 & 22.0 & 24.7 \\
\hline Range & 11.3 & 27.3 & 0.5 & 541.1 & 27.1 & 23.5 \\
\hline
\end{tabular}

Table 1. Descriptive statistics of daily polyolefin-thermal screen configuration greenhouse weather data.

RH, relative humidity; VPD, vapor pressure deficit; SR, solar radiation; DWPT, dew point temperature.

\begin{tabular}{|c|c|c|c|c|c|c|}
\hline Parameters & Temperature, ${ }^{\circ} \mathrm{C}$ & RH, $\%$ & VPD, kPa & $\mathrm{SR}, \mathrm{W} / \mathrm{m}^{2}$ & DWPT, ${ }^{\circ} \mathrm{C}$ & Fuel consumption, L \\
\hline Mean & 13.1 & 80.0 & 0.3 & 160.9 & 7.5 & 3.3 \\
\hline Variance & 5.3 & 32.8 & 0.0 & 12424.9 & 11.6 & 6.1 \\
\hline Standard deviation & 2.3 & 5.7 & 0.1 & 111.5 & 3.4 & 2.5 \\
\hline Minimum & 8.6 & 67.2 & 0.0 & 3.2 & -6.4 & 1.1 \\
\hline Maximum & 20.1 & 94.9 & 0.5 & 631.6 & 19.6 & 12.9 \\
\hline Range & 11.5 & 67.2 & 0.5 & 628.3 & 25.9 & 11.8 \\
\hline
\end{tabular}

Table 2. Descriptive statistics of daily polyolefin-thermal screen-polyethylene configuration greenhouse weather data.

RH, relative humidity; VPD, vapor pressure deficit; SR, solar radiation; DWPT, dew point temperature.

\begin{tabular}{|c|c|c|c|c|c|}
\hline Parameters & Temperature, ${ }^{\circ} \mathrm{C}$ & RH, $\%$ & $\mathrm{VPD}, \mathrm{kPa}$ & DWPT, ${ }^{\circ} \mathrm{C}$ & $\mathrm{SR}, \mathrm{W} / \mathrm{m}^{2}$ \\
\hline Mean & 5.3 & 55.6 & 0.4 & -2.9 & 321.6 \\
\hline Variance & 34.6 & 207.6 & 0.0 & 63.9 & 36937 \\
\hline Standard deviation & 5.9 & 14.4 & 0.2 & 8.0 & 192.2 \\
\hline Minimum & -9.9 & 18.2 & 0.0 & -23.8 & 24.9 \\
\hline Maximum & 19.5 & 93.4 & 1.0 & 20.0 & 783.1 \\
\hline Range & 29.4 & 75.1 & 1.0 & 43.8 & 758.2 \\
\hline
\end{tabular}

Table 3. Descriptive statistics of daily ambient weather data.

RH, relative humidity; VPD, vapor pressure deficit; DWPT, dew point temperature.; SR, solar radiation. 


\section{Results}

\section{Environmental parameters}

The descriptive statistics of the daily air temperature, $\mathrm{RH}$, VPD, solar radiation (SR), and diesel fuel consumption of the PoTS and PoTSPe greenhouses, as well as the ambient data, are reported in Tables 1-3. The mean daily air temperature, RH, VPD, solar radiation, and fuel consumption recorded were $13.0 \pm 2.3^{\circ} \mathrm{C}$, $75.8 \pm 6.5 \%, 0.4 \pm 0.1 \mathrm{kPa}, 151.9 \pm 101.8 \mathrm{~W} / \mathrm{m}^{2}$, and $5.5 \pm 3.9 \mathrm{~L}$ in the PoTS, respectively, and $13.1 \pm 2.3^{\circ} \mathrm{C}, 80 \pm 5.7 \%, 0.3 \pm 0.2 \mathrm{kPa}$, $160.9 \pm 111.5 \mathrm{~W} / \mathrm{m}^{2}$, and $3.5 \pm 2.5 \mathrm{~L}$ in the PoTSPe. The total cumulative solar radiation recorded was 1008902.5 and 1068541.3 $\mathrm{W} / \mathrm{m}^{2}$, respectively, in PoTS and PoTSPe.

The ANOVA test result is presented in Table 4, and shows that $\mathrm{RH}$, solar radiation, and fuel consumption were significantly different at both the $1 \%$ and $5 \%$ probability levels of significance, when comparing environmental parameters and fuel consumption obtained in the PoTS and PoTSPe greenhouses. However, air temperature and VPD were not significantly different. Table 5 lists the results of Tukey's honestly significance difference test (Tukey's HSD), a post hoc test, which was carried out to compare the means of the significantly different environmental parameters and fuel consumption. This test further showed that RH, VPD, solar radiation, and fuel consumption achieved in PoTS and PoTSPe were significantly different as well, at both $\alpha=0.01$ and 0.05 probability levels of significance. The critical values of the Studentised range of Q statistics obtained for RH, SR and fuel consumption were 3.67 and 2.78, 3.67 and 2.78, and 3.68 and 2.79 respectively for $\alpha$ $=0.01$ and $\alpha=0.05$.

Figures 3-6 show the trends of air temperature, RH, VPD, and leaf temperature in the PoTS and PoTSPe greenhouses, whereas Figures 7 and 8 show the trend of outside temperature against total fuel consumption and total fuel consumption, respectively. Figure 3 shows that the maximum temperatures of 20.3 and $20.1^{\circ} \mathrm{C}$ in both greenhouses occurred on the 19/11/2020 and were followed by a drop with some fluctuation between 10 and $11^{\circ} \mathrm{C}$ until $25 / 01 / 2021$ when the temperature increased to a maximum of 13.8 and $13.8^{\circ} \mathrm{C}$ in PoTS and PoTSPe, respectively. The temperature peaked again on 23/02/2021, with PoTS and PoTSPe temperatures of 17.07 and $16.99^{\circ} \mathrm{C}$, respectively, then finally dropped to 14.1 and $14.2^{\circ} \mathrm{C}$ on $02 / 03 / 2021$, at the end of the winter experiment.

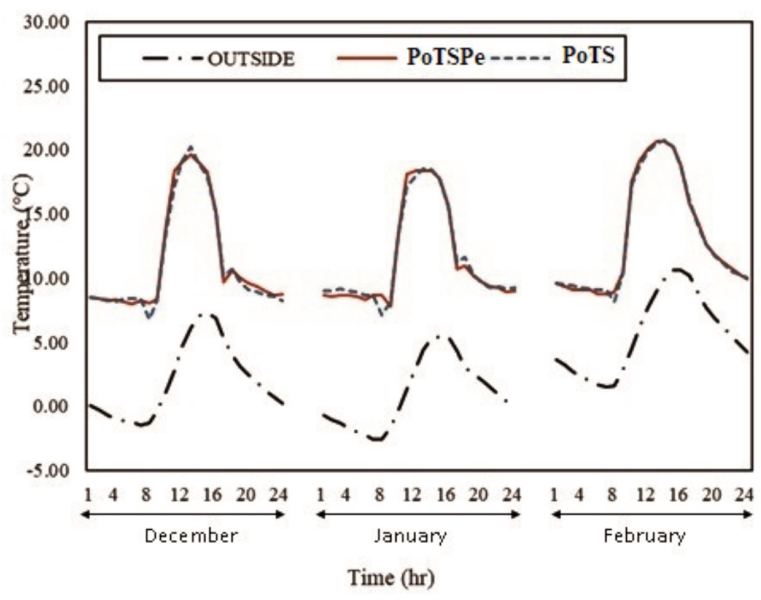

Figure 3. Polyolefin-thermal screen (PoTS), polyolefin-thermal screen-polyethylene (PoTSPe)greenhouses and ambient temperature variation.

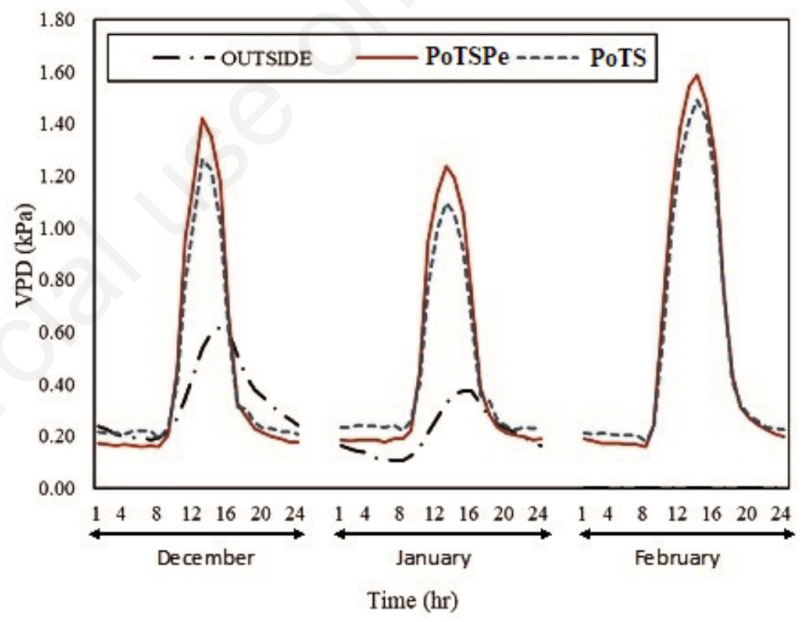

Figure 4. Polyolefin-thermal screen (PoTS), polyolefin-thermal screen-polyethylene (PoTSPe) greenhouses and ambient relative humidity $(\mathrm{RH})$ variation.

Table 4. Analysis of variance of polyolefin-thermal screen and polyolefin-thermal screen-polyethylene greenhouse environmental data.

\begin{tabular}{|c|c|c|c|c|}
\hline Parameter & df & Fstatistics & P-value & $F_{\text {critical }}$ \\
\hline PoTSTemp $v$ PoTSPeTemp & 1,262 & 0.18 & 0.67 & 3.88 \\
\hline PoTSRH us PoTSPeRH & 1,262 & 30.35 & $* * \mathrm{P}<0.05$ & 3.88 \\
\hline PoTSvipd us PoTSPevPD & 1,262 & 18.99 & $* * \mathrm{P}<0.05$ & 3.88 \\
\hline PoTS radiation Us PoTSPeradiation & 1,13278 & 23.52 & $* * \mathrm{P}<0.05$ & 3.84 \\
\hline PoTS fuel $v$ s PoTSPefuel & 1,176 & 16.7 & ${ }^{* *} \mathrm{P}<0.05$ & 3.89 \\
\hline
\end{tabular}

df, degree of freedom; PoTS, polyolefin-thermal screen; PoTSPe, polyolefin-thermal screen-polyethylene; RH, relative humidity; VPD, vapor pressure deficit. $* * P<0.05$, significant at $\alpha=1$ and $5 \%$.

Table 5. Tukey's honestly significant difference (HSD) test.

\begin{tabular}{|c|c|c|c|c|}
\hline Treatment pair & df & Tukey HSD Q statistics & Tukey HSD P-value & Tukey HSD inference \\
\hline PoTSRH vs PoTSPeRH & 2,262 & 7.79 & 0.001 & $* * \mathrm{P}<0.01$ \\
\hline PoTSvPD vs PoTSPevPD & 2,262 & 6.15 & 0.001 & $* * P<0.01$ \\
\hline PoTS radiation us PoTSPe radiation & 2,13278 & 6.86 & 0.001 & $* * \mathrm{P}<0.01$ \\
\hline PoTS fuel $v s$ PoTSPefuel & 2,176 & 5.78 & 0.001 & $* * \mathrm{P}<0.01$ \\
\hline
\end{tabular}

df, degree of freedom; PoTS, polyolefin-thermal screen; PoTSPe, polyolefin-thermal screen-polyethylene; RH, relative humidity; VPD, vapor pressure deficit. **P<0.05, significant at $\alpha=1$ and $5 \%$. 
The lowest temperatures obtained were 8.9 and $8.6^{\circ} \mathrm{C}$ in PoTS and PoTSPe, respectively, on 11/01/2021.

There were frequent fluctuations in $\mathrm{RH}$ in both the PoTS and PoTSPe greenhouses, with the same patterns in both. The maximum relative humidity values of 92.4 and $94.9 \%$ in PoTS and PoTSPe, respectively, were recorded on $02 / 03 / 2021$, whereas the minimum relative humidity values were $62.1 \%$ on $08 / 11 / 2020$ in PoTS and $67.2 \%$ on $24 / 10 / 2020$ in PoTSPe. This occurred between October and November, when mean ambient temperature was in the range of $19-21^{\circ} \mathrm{C}$. There was, on average, a $5 \%$ difference between PoTS and PoTSPe in RH readings at each point during the experiment, although the patterns of humidity fluctuations within both greenhouses were the same throughout.

At the start of the experiment, VPD in PoTS and PoTSPe was 0.5 and $0.6 \mathrm{kPa}$, respectively. The minimum and maximum VPDs recorded were 0.2 and $0.9 \mathrm{kPa}$, and 0.2 and $0.9 \mathrm{kPa}$ in PoTS and PoTSPe, respectively, on 26/01/2021 and 22/02/2021. The distribution of VPD in the PoTS greenhouse was in the ranges of 0.28 0.35 (30.3\%), 0.35-0.43 (26.5\%), 0.51-0.59 (15.2\%), 0.20-0.28 (12.1\%), $0.12-0.20(7.58 \%), 0.43-0.51(6.8 \%)$ and $0.59-0.67$ $(1.5 \%) \mathrm{kPa}$. However, in the PoTSPe greenhouse, VPD distribution was in the following ranges of $0.23-0.30$ (28.8\%), 0.30-0.47 (28.0\%), $0.15-0.23$ (12.9\%), $0.44-0.51$ (11.4\%), $0.08-0.15$ $(8.33 \%), 0.37-0.44(7.6 \%)$ and $0.51-0.59(3.0 \%) \mathrm{kPa}$. The range of 0.4-0.5 kPa was dominant in the PoTS and PoTSPe greenhouses, respectively. The PoTS and PoTSPe greenhouses had VPD readings of 17.4 and $6.06 \%$, therefore within the recommended optimum range of $0.5-1.3 \mathrm{kPa}$ reported by Shamshiri et al. (2018), respectively. Assuming other environmental parameters (air temperature, $\mathrm{CO}_{2}$ availability, root zone conditions) are also kept at optimal levels. A higher percentage of VPD readings in the PoTS greenhouse was in the range of $0.28-0.67 \mathrm{kPa}(92.4 \%)$, whereas PoTSPe greenhouse readings were mostly in the range of 0.23 to $0.59 \mathrm{kPa}(78.8 \%)$.

The descriptive statistics showed that the mean leaf temperatures were $1.7 \pm 13.5^{\circ} \mathrm{C}$ and $1.6 \pm 13.6^{\circ} \mathrm{C}$ in the PoTS and PoTSPe greenhouses, respectively. The comparison of the daily mean leaf temperature in the PoTS and PoTSPe greenhouses showed that the means were not significantly different $\left(\mathrm{df}_{1}=1, \mathrm{df}_{2}=46, \mathrm{P}<0.8\right)$.

Table 6 shows the monthly yield and ANOVA test results of the PoTS and PoTSPe greenhouses, while Figure 9 shows the total yield obtained in both greenhouses. Total yield was sorted and only the marketable fruits were considered and reported in this research.

Table 6. Monthly yield $(\mathrm{kg})$ and analysis of variance.

\begin{tabular}{lcc} 
Month & PoIS & PoISPe \\
December & 2 & 5 \\
January & 28 & 30 \\
\hline February & 45 & 38 \\
March & 12 & 11 \\
\hline Mean & 21.7 & 21.0 \\
Standard deviation & 19.0 & 15.6 \\
\hline Variance & 361.9 & 244.6 \\
Fstatistics & 0.003 & \\
\hline Fcritical & 5.99 & \\
P-value & 0.96 & \\
\hline Degrees of freedom & 1,6 & \\
\hline
\end{tabular}

PoTS, polyolefin-thermal screen; PoTSPe, polyolefin-thermal screen-polyethylene.

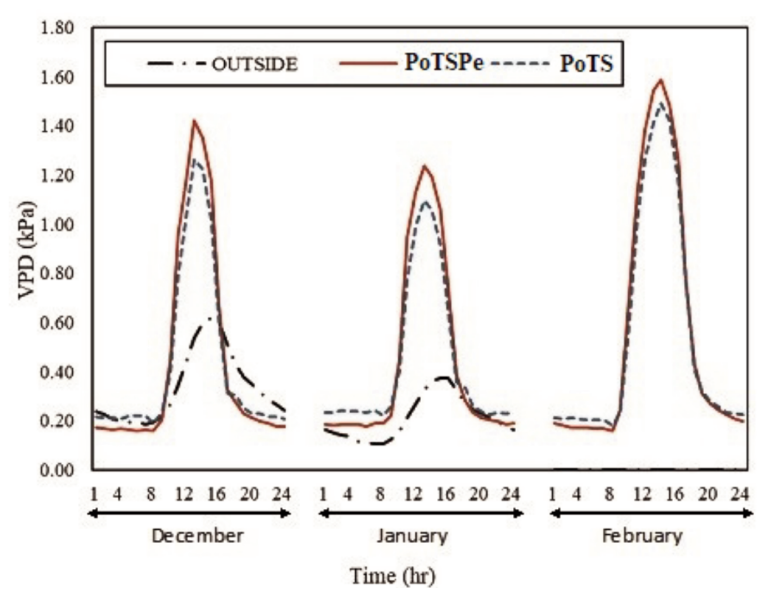

Figure 5. Polyolefin-thermal screen (PoTS), polyolefin-thermal screen-polyethylene (PoTSPe) greenhouses and ambient vapor pressure deficit (VPD) variation.

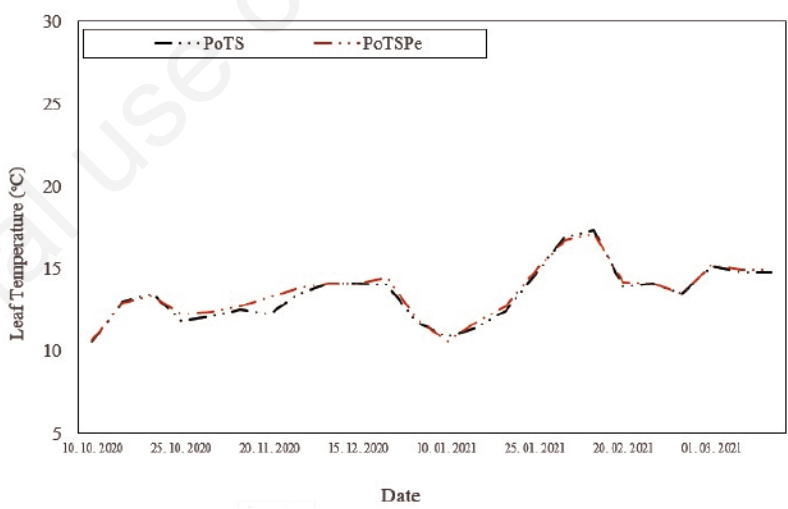

Figure 6. Trend of crop leaf temperature in the polyolefin-thermal screen (PoTS) and polyolefin-thermal screen-polyethylene (PoTSPe) greenhouses.

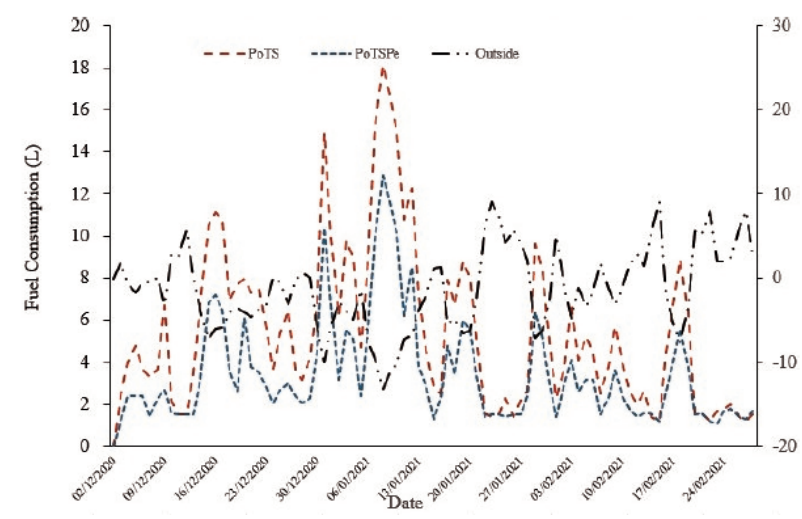

Figure 7. Trend of fuel consumption for polyolefin-thermal screen (PoTS) and polyolefin-thermal screen-polyethylene (PoTSPe) greenhouses against ambient temperature. 
Therefore, only fruits in the weight range of 25-65 g were considered in this study. The difference in the yield between PoTS and PoTSPe greenhouses was $3 \mathrm{~kg}$ and the ANOVA result shows that the difference between the yields was not significantly different.

\section{Discussion}

The temperature ranges maintained within the greenhouses were $8.93-20.2^{\circ} \mathrm{C}$ and $8.6-20.0^{\circ} \mathrm{C}$. The ambient temperature, however, was in the range of $-9.9-19.5^{\circ} \mathrm{C}$. The mean PoTS and PoTSPe greenhouse temperatures with the heating system were 18.9 and $18.6^{\circ} \mathrm{C}$ higher than the ambient temperature during the coldest period, respectively. This was achieved via the heating systems in both greenhouses. The result in this study is higher than that found by Kumar et al. (2010), who reported maximum temperature differences of 2 and $4^{\circ} \mathrm{C}$ in Sawtooth and Quonset greenhouses, respectively, with respect to ambient temperature in winter in India. Maintaining an optimum average daily air temperature is crucial for pollen development, as well as to maintain a good anther in tomato flowers. High temperatures reduce growth, cause heat stress, and result in ineffectual transpiration. Bradford et al. (2010) reported a temperature range of $14-26^{\circ} \mathrm{C}$ for Honeoye, RH30, and Tribute varieties of strawberry, and Sim et al., (2020) reported a mean air temperature of $25^{\circ} \mathrm{C}$, which is higher than the mean air temperatures of 13 and $13.1^{\circ} \mathrm{C}$ recorded in the PoTS and PoTSPe greenhouses, respectively. Villarreal-Guerrero et al. (2020) reported a mean temperature of $23.5 \pm 0.99^{\circ} \mathrm{C}$. According to Ariana et al. (2011) and Velasco-López et al. (2020), a greenhouse temperature of $27.5^{\circ} \mathrm{C}$ is suitable and favourable for strawberry growth, development and fruition, while Jayasekara et al. (2018) recorded a temperature range of $15-25^{\circ} \mathrm{C}$ for air-inflated and conventional greenhouses used for strawberry cultivation.

The RH ranges recorded in the PoTS and PoTSPe greenhouses

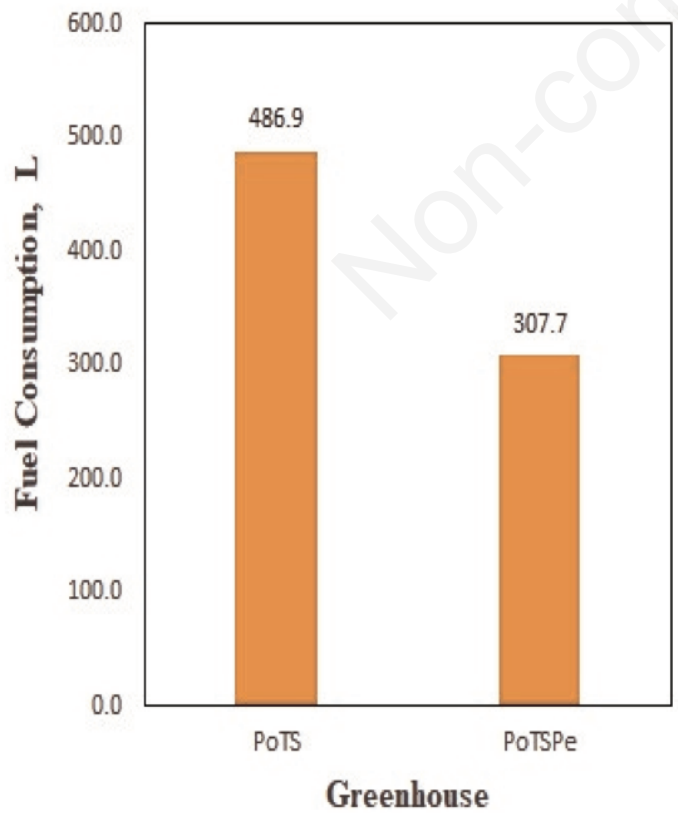

Figure 8. Total fuel consumption for polyolefin-thermal screen (PoTS) and polyolefin-thermal screen-polyethylene (PoTSPe) greenhouses. were $65.1-92.4 \%$ and $67.2-95 \%$, respectively. The ambient $\mathrm{RH}$, however, was in the range of $89.5-98.2 \%$. The range reported in this study is higher than the range of $65-75 \%$ reported for optimum growth and development of greenhouse strawberries that maximizes the yield, good fruit size, and fruit set in strawberries (Elsanta variety) (Lieten, 2002). Sim et al., (2020) reported an optimal air RH of $73.7 \%$, and Villarreal-Guerrero et al. (2020) reported a mean $\mathrm{RH}$ value of $4.9 \pm 68.6 \%$. RH within the greenhouse is maintained within the threshold values to minimize the transpiration rate in plants, as humidity above the threshold is detrimental to plant growth, development, tip burn, fruition, fruit firmness, and shelf life. High humidity promotes the growth of mould, bacteria, and pests such as fungus gnats, as well as conditions like root or crown rot, especially in strawberries. A low RH results in a low water uptake, resulting in water stress, thereby causing the closure of the plant stomates to reduce the loss of excess vapor and consequently limiting photosynthesis. Lieten (2002), Shamshiri et al. (2018), and (Sim et al., 2020) reported an increase in the RH in the greenhouses enhances vegetative growth, yet long-term exposure to high humidity significantly increases the leaf area and the length of petioles at the expense of fruition or tuberization. However, prolonged exposure to low $\mathrm{RH}$ is dangerous, as it results in water stress.

The VPD ranges achieved in PoTS and PoTSPe were 0.1-0.6 and $0.1-0.5 \mathrm{kPa}$, respectively. It is worthy to note that 92.4 and $85 \%$ of the VPD readings recorded in PoTS and PoTSPe greenhouses respectively were within the range of 0.2 to $0.6 \mathrm{kPa}$. Sim et al. (2020) reported a range of 0.1 to $0.45 \mathrm{kPa}$ for strawberrys. VPD values between 0.8 and $1.1 \mathrm{kPa}$ are considered optimal, with 0.5 and $1.3 \mathrm{kPa}$ as the lowest and highest extremes, respectively, which increase the risk for fungal attack, mineral deficiencies, wilting and physiological disorders in most plants (Shamshiri et al., 2018). VPD also influences greenhouse energy demand, which invariably affects the cost of controlling the temperature and $\mathrm{RH}$,

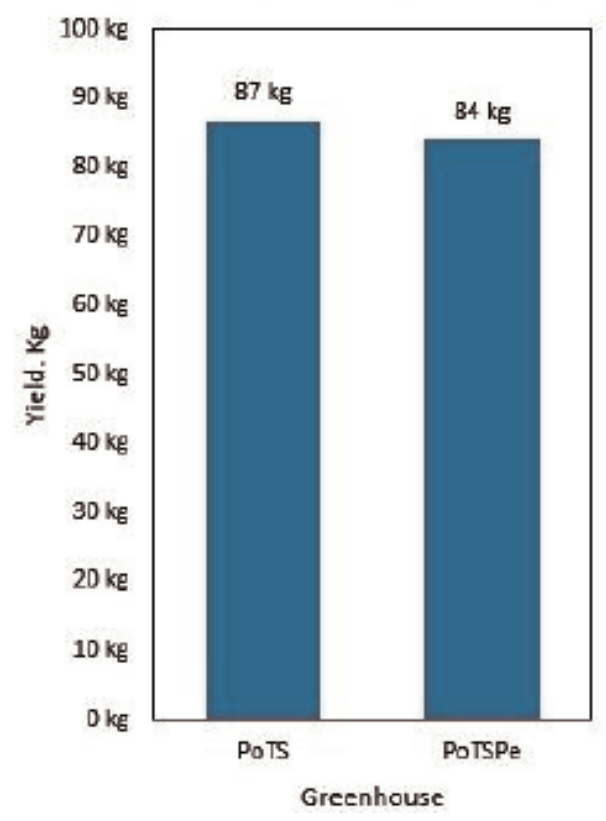

Figure 9. Total yield for polyolefin-thermal screen (PoTS) and polyolefin-thermal screen-polyethylene (PoTSPe) greenhouses. 
from which VPD is derived. Too low $(<0.5 \mathrm{kPa})$ or too high $(>1.3$ $\mathrm{kPa}$ ) VPDs require dehumidification or humidification, respectively. However, Lu et al. (2015) recommended to maintain an average VPD within a range of 0.8-1.4 $\mathrm{kPa}$. In another study, VillarrealGuerrero et al. (2020) reported a mean VPD value of $0.9 \pm 0.2 \mathrm{kPa}$, while Jayasekara et al. (2018) recorded a range of 0.03-0.2 kPa in an air-inflated double-layer greenhouse used for strawberry cultivation.

The mean monthly solar radiation values recorded inside the PoTS and PoTSPe greenhouses and in the external environment in January, February, and March were 548.0, 581.3, and $704.7 \mathrm{~W} / \mathrm{m}^{2}$; $544.6,576.9$, and $697.4 \mathrm{~W} / \mathrm{m}^{2}$; and $142.1,151.2$, and $251.6 \mathrm{~W} / \mathrm{m}^{2}$, respectively. The values recorded in this study exceeded the range of 10.75-360.99 W/m² reported by Torres and Lopez (2011) for strawberries. Sim et al. (2020), however, reported a very low solar radiation value of $130.80 \mathrm{~W} / \mathrm{m}^{2}$, and Jayasekara et al. (2018) reported a range of $0-420 \mathrm{~W} / \mathrm{m}^{2}$ with a conventional double layer and $0-400 \mathrm{~W} / \mathrm{m}^{2}$ in an air-inflated greenhouse.

The daily mean leaf temperature in the PoTS and PoTSPe greenhouses had a range of $10.6-17.4^{\circ} \mathrm{C}$, and $10.6-17.2^{\circ} \mathrm{C}$, respectively. The recommended optimal mean leaf temperature range for greenhouse crops is $10-19^{\circ} \mathrm{C}$ (Katsoulas and Stanghellini, 2019), although Ganguly and Bauri (2014) reported $26^{\circ} \mathrm{C}$ for greenhouse crops. Despite the single layer of polyolefin, the PoTS was able to keep the plants within the optimal leaf temperature range to achieve optimum growth, development, and yield.

Thermal screens were used in combination with a cooling system or multiple cooling systems in a hot climate to keep greenhouse air temperature lower than the ambient air temperature, thereby, causing an increase in the level of RH (decrease in VPD) and a decrease in the percentage of transmitted solar radiation. However, in this study the thermal screen was used only at night to insulate the greenhouse microclimate and reduce significantly energy demand during the cold winter nights. Therefore, the use of thermal screens in this experiment was intended to serve as an energy-saving strategy. The greenhouses were evaluated in terms of fuel consumption used for heating the greenhouse air space during winter. The highest consumption was in January 2021 with PoTS and PoTSPe recording 18.1 and $12.9 \mathrm{~L} / 24 \mathrm{hr}$, respectively, whereas the lowest consumption of 1.2 and $1.1 \mathrm{~L}$ for PoTS and PoTSPe, respectively, was recorded in December 2020. The quantity of fuel consumed in PoTS can be attributed to the glazing configuration, which allowed greater interference from the ambient weather on the greenhouse microclimate, thus requiring more frequent and prolonged heating than with PoTSPe. Night-time greenhouse air temperatures in PoTS and PoTSPe were higher than the ambient night-time air temperature by 18.9 and $18.6^{\circ} \mathrm{C}$, respectively. However, Ahemd et al. (2016) reported a lower percentage of conserved energy in the range of $15-20 \%$ of the heating energy and a $5{ }^{\circ} \mathrm{C}$ higher night-time greenhouse air temperature than ambient air temperature using a shading material only. Bailey (1981), however, reported that thermal screens cause a build-up of thermal energy levels within the greenhouse microclimate, thereby reducing energy demand to approximately $35-60 \%$ at night in cold regions. Figure 7 shows the trend of fuel consumption throughout the experiment in winter (December to March). Consumption was the highest between 2020/12/30 and 2021/01/20. Figure 8 shows the total fuel consumption in each greenhouse, where PoTS had the highest fuel consumption. A total of $794.6 \mathrm{~L}$ of diesel was consumed by both greenhouses. In particular, the PoTS greenhouse consumed 486.9 L and the PoTSPe greenhouse consumed 307.7 L. The descriptive fuel consumption statistics showed that the mean quantities of fuel consumed for heating the PoTS and PoTSPe greenhouses were $5.5 \pm 3.9 \mathrm{~L}$ and $3.5 \pm 2.5 \mathrm{~L}$, respectively. Since at the time of the study the price of diesel was W1,312.63 per litre ( $€$
0.97) in South Korea, the cost of running the boiler throughout the experimental period in PoTS and PoTSPe was W639,119.00 (€473.08) and W403,896.00 (€298.96), respectively. The estimated cost of installing the inner layer of polyethylene in the PoTSPe was $\mathrm{W} 120,000.00$ (€88.82). The life span of the polyethylene layer is about 3 years, therefore it is not cost-effective to operate the PoTS greenhouse in winter due to the significant energy cost incurred.

The ANOVA result presented in Table 4 shows that the difference in fuel consumption by both greenhouses was significant $(\mathrm{F}(1,176)=3.89 ; \mathrm{P}<0.01)$. As can be seen, the second layer of polyethylene in the PoTSPe greenhouse was able to trap more heat energy, which caused a higher temperature increase during cold nights and thereby reduced the quantity of fuel required by the water boiler and air space heater. The reduction in the quantity of fuel consumed was achieved by reducing the frequency and duration of the greenhouses heating cycles. However, the opposite was recorded in the PoTS greenhouse, which lead to the consumption of more fuel to heat the greenhouse air space. As can be observed in Figure 7, fuel consumption in both greenhouses (PoTS and PoTSPe) followed the same variation trend, which demonstrated that both greenhouses responded to changes in the ambient weather with the same pattern. However, the effect of the ambient environment on the PoTS was greater, as the boiler and air heater were triggered more often to adjust its microclimate to the minimum temperature set point of $18^{\circ} \mathrm{C}$, especially at night and on cold days The larger effect of the ambient environmental condition recorded on the PoTS was a result of the single layers of polyolefin and the thermal screen, whereas the PoTSPe had single layers of polyolefin, thermal screen and polyethylene. The polyethylene layer created a vacuum between itself and the thermal screen, which served as insulation, thus increasing the temperature and reducing the humidity build-up rate. This led to VPD levels in the range of 0.1-0.6 and 0.0-0.5 kPa recorded in PoTS and PoTSPe greenhouses. However, PoTS had $90 \%$ of VPD readings in the range of 0.2 $0.7 \mathrm{kPa}$, while $78.8 \%$ of VPD readings for PoTSPe were in the range of 0.23 to $0.59 \mathrm{kPa}$.

\section{Conclusions}

The use of two layers of polyolefin in combination with a single layer of thermal screen resulted in saving $58.2 \%$ of energy in the PoTSPe greenhouse. The experimental data from the singlelayer polyolefin, in combination with a single layer of a thermal screen, has shown that more heat energy was lost. Therefore, more fuel was consumed during the cold winter nights to heat the greenhouse atmosphere. Finally, PoTS was able to provide the optimum environmental condition required for strawberry production, as is evident from the resulting environmental and yield data recorded. However, it is uneconomical to operate a PoTS greenhouse, as it costs more to heat up the greenhouse micro-environment than installing an inner layer of polyethylene as an insulation over the thermal screen inner surface.

\section{References}

Ahemd H.A., Al-Faraj A.A., Abdel-Ghany A.M. 2016. Shading greenhouses to improve the microclimate, energy and water saving in hot regions: a review. Sci. Hortic. 201:36-45.

Bonachela S., Granados M.R., López J.C., Hernández J., Magán J.J., Baeza E.J., Baille A. 2012. How plastic mulches affect the thermal and radiative microclimate in an unheated low-cost greenhouse. Agric. Forest Meteorol. 152:65-72. 
Bradford E., Hancock J.F., Warner R.M. 2010. Interactions of temperature and photoperiod determine expression of repeat flowering in strawberry. Hortic. Sci. 135:102-107.

Choi H., Moon T., Jung D.H., Son J.E. 2019. Prediction of air temperature and relative humidity in greenhouse via a multilayer perceptron using environmental factors. Protect. Hortic. Plant Factory. 28:95-103.

Fernandez G., Butler L., Louws F. 2001. Strawberry growth and development in an annual plasticulture system. HortSci. $36: 1219-23$

Ganguly A., Bauri B. 2014. Parametric and performance analysis of a naturally ventilated floriculture greenhouse using a thermal model. Procedia Engine. 90:485-90.

Hernández J., Bonachela S., Granados M.R., López J.C., Magán J.J., Montero J.I. 2017. Microclimate and agronomical effects of internal impermeable screens in an unheated Mediterranean greenhouse. Biosyst. Engine. 163:66-77.

Jayasekara S.N., Na W.H., Owolabi A.B., Lee J.W., Rasheed A., Kim H.T., Lee H.W. 2018. Comparison of environmental conditions and insulation effect between air inflated and conventional double layer greenhouse. Protect. Hortic. Plant Factory. 27:46-53.

Katsoulas N., Kittas C. 2008. Impact of greengouse microclimate on plant growth and development with special reference to the solanaceae. Eur. J. Plant Sci. Biotechnol. 2:31-40.

Katsoulas N., Stanghellini C. 2019. Modelling crop transpiration in greenhouses: different models for different applications. Agronomy 9:2-17.

Kumar K.S., Jha M.K., Tiwari K.N., Singh A. 2010. Modeling and evaluation of greenhouse for floriculture in subtropics. Energy Build. 42:1075-83.

Lieten P. 2002. The effect of humidity on the performance of greenhouse grown strawberry. Acta Hortic. 567:479-82.

Lu N., Nukaya T., Kamimura T., Zhang D., Kurimoto I., Takagaki M., Maruo T., Kozai T., Yamori W. 2015. Control of vapor pressure deficit (VPD) in greenhouse enhanced tomato growth and productivity during the winter season. Sci. Hortic. 197:1723.

Mijinyawa Y. 2011. Greenhouse farming as adaptation to climate change. J. Agric. Sci. Technol. 5:943-9.

Omobowale M.O. 2019. Evaluation of a low-cost greenhouse for controlled environment cultivation of sweet pepper. Arid Zone J. Engine. Technol. Environ. 16: 28-36.

Piscia D., Montero J.I., Bailey B., Muñoz P., Oliva A. 2013. A new optimisation methodology used to study the effect of cover properties on night-time greenhouse climate. Biosyst. Engine. 116:130-43.

Rasheed A., Lee J.W., Kim H.T., Lee H.W. 2019. Efficiency of different roof vent designs on natural ventilation of single-span plastic greenhouse. Protect. Hortic. Plant Factory. 28:225-33

Shamshiri R.R., Jones J.W., Thorp K.R., Ahmad D., Che Man H., Taheri S. 2018. Review of optimum temperature, humidity, and vapour pressure deficit for microclimate evaluation and control in greenhouse cultivation of tomato: a review. Int. Agrophys. 32:287-302.

Sim H.S., Kim D.S., Ahn M.G., Ahn S.R., Kim S.K. 2020. Prediction of strawberry growth and fruit yield based on environmental and growth data in a greenhouse for soil cultivation with applied autonomous facilities. Hortic. Sci. Technol. 38:840-9.

Torres A.P., Lopez R.G. 2011. Photosynthetic daily light integral during propagation of Tecoma stans influences seedling rooting and growth. Hortic. Sci. 46:282-6.

Velasco-López F., Martínez-Gutiérrez G.A., Morales I., VasquezLópez A., Escamirosa-Tinoco C. 2020. Photosynthetically active radiation in strawberry produced in stair-like containers. Hortic. Brasil. 38:5-11.

Villarreal-Guerrero F., Pinedo-Alvarez A., Flores-Velázquez J. 2020. Control of greenhouse-air energy and vapor pressure deficit with heating, variable fogging rates and variable vent configurations: simulated effectiveness under varied outside climates. Comput. Electron. Agricult. 174:105515. 